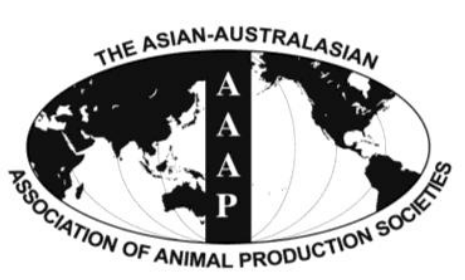

Open Access

Asian Australas. J. Anim. Sci.

Vol. 27, No. 7 : 1019-1025 July 2014

http://dx.doi.org/10.5713/ajas.2013.13734

www.ajas.info

pISSN 1011-2367 elSSN 1976-5517

\title{
Effects of Crossbreeding and Gender on the Carcass Traits and Meat Quality of Korean Native Black Pig and Duroc Crossbred
}

\author{
Muhlisin $^{1,2}$, Panjono ${ }^{2}$, Sung-Jin Lee ${ }^{3}$, Jeong Koo Lee ${ }^{4}$, and Sung Ki Lee ${ }^{1, *}$ \\ ${ }^{1}$ Department of Animal Products and Food Science, Kangwon National University, Chuncheon 200-701, Korea
}

\begin{abstract}
This study was conducted to observe the effects of crossbreeding and gender on the carcass traits and meat quality of Korean Native Black Pig (KNP) and KNP $\times$ Duroc crossbred $(\mathrm{KNP} \times \mathrm{D})$. A total of 50 pigs comprising seven KNP barrows, eight KNP gilts, twenty $\mathrm{KNP} \times \mathrm{D}$ barrows and fifteen $\mathrm{KNP} \times \mathrm{D}$ gilts were used in this study. Animals were reared in the same housing condition with same feed diet for six months prior to slaughter. After an overnight chilling, the carcasses were graded, and samples of Musculus longissimus dorsi were obtained for meat quality analysis. The slaughter and carcass weights and dressing percentage of KNP $\times \mathrm{D}$ were higher $(p<0.001)$ than those of KNP. The slaughter and carcass weights and backfat thickness of barrows were higher $(p<0.01)$ than those of gilts. There were no significant difference in carcass conformation and quality grade between KNP and KNP $\times \mathrm{D}$ as well as barrow and gilt. Fat content of KNP $\times$ D was higher $(p<0.001)$ than that of KNP. Fat content of barrow was higher $(p<0.001)$ than that of gilt. There was interaction between crossbreeding and gender on the fat content. KNP gilt showed higher fat content than KNP barrow whereas $\mathrm{KNP} \times \mathrm{D}$ barrow showed higher fat content than $\mathrm{KNP} \times \mathrm{D}$ gilt. Lightness, redness, yellowness, chroma and hue angle values and color preference of meat of $\mathrm{KNP} \times \mathrm{D}$ were lower $(\mathrm{p}<0.001)$ than those of KNP. Redness, yellowness and chroma values of meat of barrow were lower $(\mathrm{p}<0.05)$ than those of gilt. It is concluded that crossbreeding KNP with Duroc increases carcass productivity and meat fat but decreases meat color values and preference. Crossbreeding of KNP with Duroc produces a better fat deposition in meat of barrows than in gilts. (Key Words: Korean Native Black Pig, Duroc, Crossbreeding, Gender, Carcass Traits, Meat Quality)
\end{abstract}

\section{INTRODUCTION}

Korean native black pig (KNP) is known for its high redness value and high content of intramuscular fat which are in high demand by consumers (Jin et al., 2001) and also its strong tolerance of diseases (RDA, 2001). However, due to its slow growth rate and light carcass weight, it has been crossbred with commercial breeds to improve its productivity (Park et al., 2007; Hwang et al., 2004; Kim et al., 2013).

\footnotetext{
* Corresponding Author: Sung Ki Lee. Tel: +82-33-250-8646, Fax: +82-33-251-7719, E-mail: skilee@kangwon.ac.kr

2 Faculty of Animal Science, Universitas Gadjah Mada, Yogyakarta 55281, Indonesia.

3 Department of Animal Biotechnology, Kangwon National University, Chuncheon 200-701, Korea.

${ }^{4}$ Department of Animal Resources Science, Kangwon National University, Chuncheon 200-701, Korea.

Submitted Nov. 21, 2013; Revised Feb. 3, 2014; Accepted Mar. 10, 2014
}

One of the commercial breeds widely used in the KNP crossbreeding program is the Duroc pig resulting in $\mathrm{KNP} \times$ Duroc crossbred $(\mathrm{KNP} \times \mathrm{D})$. Duroc is usually used as a sire breed due to its higher feed intake, better feed conversion ratio (Raj et al., 2010), excellent growth rate that is important factor for fattening pig production (Suzuki et al., 2002), and better average daily gain (Latorre et al., 2003b). Alonso et al. (2009) stated that carcass traits of Duroc lines (progeny of crossbreeding with Duroc) are better than traits of original pure lines without any loss of meat quality. In addition to its advantages in intramuscular fat deposition and carcass traits, Duroc reportedly has a good feed conversion ratio and adequate daily gains that produce a faster growth than other breeds such as Large White pigs, Pietrain and its crossed breeds (Blanchard et al., 1999; Lattore et al., 2003b). Furthermore, Cameron et al. (1990) suggested that the introduction of Duroc to a pig breeding program may help to improve the meat and eating quality. Alonso et al. (2009) who studied crossbreeding 
between Duroc and LandracexLarge White found that crossbreeding with Duroc improved the intramuscular fat. Franco et al. (2014) reported that crossbreeding with Duroc improved the carcass quality (carcass compactness, ham percentage and killing percentage) of Celta pig.

Due to its potential, the use of Duroc in cross breeding to improve meat production has increased dramatically over recent years. However, there is very little information related to the effect of crossbreeding using Duroc on the carcass traits and meat quality of KNP. Therefore, this study was conducted to observe the effects of crossbreeding and gender on the carcass traits and meat quality of KNP and $\mathrm{KNP} \times \mathrm{D}$.

\section{MATERIAL AND METHODS}

\section{Experimental animals}

A total of 50 head of pigs comprising of seven KNP barrows, eight $\mathrm{KNP}$ gilts, twenty $\mathrm{KNP} \times \mathrm{D}$ barrows and fifteen $\mathrm{KNP} \times \mathrm{D}$ gilts were used in this study. $\mathrm{KNP} \times \mathrm{D}$ pigs were the offspring of KNP sows sired by Duroc boar. Animals were reared in the experimental station of Kangwon National University (Chuncheon, South Korea). Animals were reared in the same housing condition with the same diet for six months prior to slaughter. The day before slaughter, the animals were weighed for determination of slaughter weight. The pigs were then transported to a commercial slaughterhouse. The pigs were electrically stunned and slaughtered according to industry standards. After an overnight chilling, the carcasses were weighed (carcass weight) and graded. Dressing percentage was calculated as follows:

$$
\text { Dressing percentage }(\%)=\frac{\text { Carcass weight }}{\text { Slaughter weight }} \times 100
$$

The samples of Musculus longissimus dorsi from the left side of carcasses were taken and packed by vacuum packaging. The samples were transported to the Laboratory of Meat Science, Kangwon National University, for meat quality analyses.

\section{Carcass traits}

The carcass grading was performed by pork grading experts according to Korean grading standards for pork (Korea Institute for Animal Products Quality Evaluation, 2010). The quality grading was done based upon the characteristics such as marbling, lean color, and condition of belly streaks and was scored as 4 point for $1^{+}$grade, 3 point for 1 grade, 2 for 2 grade and 1 point for 3 grade. The conformation grade was determined by assessing carcass weight, backfat thickness, balance, muscle and fat condition, finish, etc., and was scored as 4 point for A grade, 3 point for $\mathrm{B}$ grade, 2 point for $\mathrm{C}$ grade and 1 point for $\mathrm{D}$ grade.

\section{Meat quality}

Meat quality analysis included chemical, physical and sensory properties. Chemical properties included the proximate analyses. The samples of Longissimus dorsi were ground through a $3 \mathrm{~mm}$ plate using a meat grinder (DFG 450, Daehan Food Machine Co., Ltd., Kimpo, Korea). Crude fat (intramuscular fat) content was analyzed using the Soxhlet method (AOAC, 2007). Two grams of sample were placed on a filter paper (Whatman No. 1) and dried at $105^{\circ} \mathrm{C}$ overnight. The fat content was extracted with diethyl ether (J. T. Baker, Philipsburg, New Jersey, USA) on soxhlet tube for $46 \mathrm{~h}$. The fat that was removed during extraction is determined as crude fat contained in sample. Moisture, crude protein and ash content analyses also were performed by using methods of Association of Official Analytical Chemists (AOAC, 2007).

Physical properties analyses included $\mathrm{pH}$ value, drip loss, cooking loss, Warner-Bratzler shear force (WBSF) and Commission Internationale de I'Eclairage (CIE) color values of meat. For $\mathrm{pH}$ measurement, $10 \mathrm{~g}$ of sample was homogenized with $100 \mathrm{~mL}$ of distilled water at 10,000 rpm for $60 \mathrm{~s}$ using a homogenizer (PH91, SMT Co. Ltd., Tokyo, Japan). The $\mathrm{pH}$ of meat slurry at room temperature was measured using a $\mathrm{pH}$ meter (SevenEasy $\mathrm{pH}$, Mettler-Toledo $\mathrm{GmbH}$, Greifensee, Switzerland).

Drip loss was measured by preparing approximately 30 $\mathrm{g}$ of sample in polyethylene bags and stored at $5^{\circ} \mathrm{C}$ for $24 \mathrm{~h}$. The water extruded from the sample was removed and sample was weighed. The drip loss was calculated as follows:

$$
\text { Drip loss }(\%)=\frac{\mathrm{Wi}-\mathrm{Wt}}{\mathrm{Wi}} \times 100
$$

$\mathrm{Wi}=$ Weight of sample before storing $(\mathrm{g})$

$\mathrm{Wt}=$ Weight of sample after $24 \mathrm{~h}$ of storing $(\mathrm{g})$

To determine the cooking loss, $100 \mathrm{~g}$ of sample was placed in a polyethylene bag and immersed in a water bath at $85^{\circ} \mathrm{C}$ until the internal temperature of sample reached $75^{\circ} \mathrm{C}$, requiring about $30 \mathrm{~min}$. The sample was cooled at room temperature for $30 \mathrm{~min}$. The initial weights of uncooked and cooked meat were recorded, and the cooking loss was calculated as follows:

$$
\text { Drip loss }(\%)=\frac{\mathrm{Wu}-\mathrm{Wc}}{\mathrm{Wu}} \times 100
$$

$\mathrm{Wu}=$ Weight of uncooked meat $(\mathrm{g})$

$\mathrm{Wc}=$ Weight of cooked meat $(\mathrm{g})$

The cooked samples were cut into cubes $(1 \times 1 \times 1 \mathrm{~cm})$ for WBSF measurements using a texture analyzer (TA-XT2 $i$ 
version 6.06, Stable Micro Systems Ltd., Surrey, England). The measurement was performed according to DeHuidobro et al. (2005).

Color changes of the surface of samples were monitored by measuring the CIE color values including lightness $\left(\mathrm{L}^{*}\right)$, redness $\left(\mathrm{a}^{*}\right)$, yellowness $\left(\mathrm{b}^{*}\right)$, Chroma $\left(\mathrm{C}^{*}\right)$ and Hue-angle $\left(h^{\circ}\right)$ by using a color difference meter (CR-400, Konica Minolta Sensing Inc., Osaka, Japan) and an illuminant C. Chroma and hue angle were calculated using the equations; chroma $\mathrm{C}=\left(\mathrm{a}^{2}+\mathrm{b}^{2}\right)^{0.5}$, and hue-angle $=\tan ^{-1}$ (b/a) (Hunt et al., 1991). The color instrument was calibrated using white plate $(\mathrm{Y}=93.6, \mathrm{x}=0.3134$, and $\mathrm{y}=0.3194)$. Ten times random measurements were taken from each sample after 1 $\mathrm{h}$ blooming at room temperature as described by Lee et al. (2008)

Sensory properties analyses included color of fresh meat and taste and texture of cooked meat. After $1 \mathrm{~h}$ of blooming at room temperature, fresh meat was provided to panelists for color evaluation. Ten milliliters of soybean oil were heated in a pan with medium heat for cooking meat. The fresh sample was sliced into $1 \mathrm{~cm}$ thickness and then fried in a pan for $10 \mathrm{~min}$, with 4 times flipping in every $2.5 \mathrm{~min}$. The fried pork was cut into approximately $1 \times 1 \times 1 \mathrm{~cm}^{3}$ in size and provided to panelists for taste and texture evaluation. A hundred untrained panelists participated in this sensory evaluation. The panelist evaluated the sample using a 9-point hedonic scale, where 1 was regarded as very bad and 9 was regarded as very good.

\section{Statistical analysis}

Analysis of variance was performed using SPSS version 19.0 software (SPSS, 2010) GLM procedures with $2 \times 2$ factorial arrangement of treatment. The model included crossbreeding (KNP, KNP $\times \mathrm{D})$, gender (barrow, gilt) and their interaction. Data are presented as means \pm standard deviation. When the crossbreeding and gender effect was significant $(\mathrm{p}<0.05)$, paired $t$-test was used at the $5 \%$ level to perform pairwise comparison among sample means.

\section{RESULTS AND DISCUSSION}

\section{Carcass traits}

The slaughter and carcass weights and dressing percentage of $\mathrm{KNP} \times \mathrm{D}$ were higher $(\mathrm{p}<0.001)$ than those of KNP (Table 1). This showed that the cross breeding of KNP with Duroc improved the slaughter and carcass weight of KNP. This was in accordance with Franco et al. (2014) who found that Celta pig crossed with Duroc grew faster and had higher body weight and dressing percentage than Celta pig purebred with same feeding period. The slaughter and carcass weights of barrows were higher $(p<0.01)$ than those of gilts (Table 1). This was in accordance with Cisneros et al. (1996) who reported that barrows grew faster than gilts during same period of rearing with same feed and Latorre et al. (2003b) who reported that the barrows grew faster and produce heavier carcasses than gilts. However, there were no significant difference in dressing percentage between barrows and gilts (Table 1). Similar dressing percentage between barrows and gilts was also reported by Lottere et al. (2003b), Lo Fiego et al. (2005) and Peinado et al. (2008). There was no interaction between crossbreeding and gender on the slaughter and carcass weights and dressing percentages (Table 1). Crossbreeding of KNP with Duroc produced a similar effect on carcass quantity of both barrows and gilts.

There was no significant difference in backfat thickness between KNP and KNP×D (Table 1). This showed that the greater slaughter and carcass weight of $\mathrm{KNP} \times \mathrm{D}$ was not accompanied by higher backfat thickness. This finding was not in accordance with McGloughin et al. (1988) who stated that the advantages of Duroc as quality improver through crossbreeding might be offset by the greater backfat thickness and heavier shoulder. This might due to the high fat deposition of KNP. Backfat thickness of barrows was higher $(\mathrm{p}<0.001)$ than that of gilts (Table 1). This was in accordance with Latorre et al. (2003b) who reported that the barrows of Duroc and crossbreds had thicker back fat than gilts. There was no interaction between crossbreeding and

Table 1. Carcass traits ${ }^{1}$ of Korean Native Black Pig and its crossbred with Duroc pig

\begin{tabular}{|c|c|c|c|c|c|c|c|}
\hline \multirow{2}{*}{ Items } & \multicolumn{2}{|c|}{ Crossbreeding effect (C) } & \multirow{2}{*}{$\mathrm{p}$ value ${ }^{2}$} & \multicolumn{2}{|c|}{ Gender effect $(\mathrm{G})$} & \multirow{2}{*}{$\mathrm{p}$ value ${ }^{2}$} & \multirow{2}{*}{$\begin{array}{l}\mathrm{p} \text { value }^{2} \text { of } \\
\text { interaction } \\
\quad(\mathrm{C} \times \mathrm{G})\end{array}$} \\
\hline & KNP & $\mathrm{KNP} \times \mathrm{D}$ & & Barrow & Gilt & & \\
\hline$\overline{\text { Slaughter weight (kg) }}$ & $67.13 \pm 9.59$ & $103.21 \pm 9.74$ & 0.000 & $96.88 \pm 18.47$ & $86.09 \pm 19.31$ & 0.009 & 0.749 \\
\hline Carcass weight (kg) & $49.13 \pm 6.94$ & $77.97 \pm 7.95$ & 0.000 & $73.15 \pm 14.66$ & $64.83 \pm 15.23$ & 0.009 & 0.712 \\
\hline Dressing percentage $(\%)$ & $73.22 \pm 1.80$ & $75.92 \pm 2.20$ & 0.000 & $75.43 \pm 2.02$ & $74.66 \pm 2.81$ & 0.351 & 0.688 \\
\hline Back fat thickness (mm) & $24.40 \pm 4.68$ & $26.66 \pm 4.69$ & 0.173 & $28.29 \pm 4.44$ & $23.21 \pm 3.58$ & 0.000 & 0.546 \\
\hline Conformation grade ${ }^{3}$ & $2.00 \pm 0.00$ & $1.88 \pm 0.33$ & 0.182 & $1.92 \pm 0.27$ & $1.90 \pm 0.30$ & 0.838 & 0.838 \\
\hline Quality grade ${ }^{4}$ & $1.87 \pm 0.51$ & $1.87 \pm 0.33$ & 0.479 & $2.00 \pm 0.48$ & $1.91 \pm 0.66$ & 0.838 & 0.491 \\
\hline
\end{tabular}

KNP, Korean Native Black Pig; KNP×D, Korean Native Black Pig crossbred with Duroc.

${ }^{1}$ Values were presented as mean \pm standard deviation. ${ }^{2} \mathrm{p}<0.05$ was considered as significantly different.

${ }^{3} \mathrm{~A}$ grade $=4$ point, $\mathrm{B}$ grade $=3$ point, $\mathrm{C}$ grade $=2$ point, and $\mathrm{D}$ grade $=1$ point.

${ }^{4} 1^{+}$grade $=4$ point, 1 grade $=3$ point, 2 grade $=2$ point , and 3 grade $=1$ point. 
Table 2. Proximate and physical qualites ${ }^{1}$ of Musculus longissimus dorsi of Korean Native Black Pig and its crossbred with Duroc pig

\begin{tabular}{|c|c|c|c|c|c|c|c|}
\hline \multirow{2}{*}{ Items } & \multicolumn{2}{|c|}{ Crossbreeding effect (C) } & \multirow{2}{*}{$\mathrm{p}$ value ${ }^{2}$} & \multicolumn{2}{|c|}{ Gender effect $(\mathrm{G})$} & \multirow{2}{*}{$\mathrm{p}$ value ${ }^{2}$} & \multirow{2}{*}{$\begin{array}{l}\mathrm{p} \text { value }{ }^{2} \text { of } \\
\text { interaction } \\
\quad(\mathrm{C} \times \mathrm{G})\end{array}$} \\
\hline & $\mathrm{KNP}^{2}$ & $\mathrm{KNP} \times \mathrm{D}^{2}$ & & Barrow & Gilt & & \\
\hline \multicolumn{8}{|l|}{ 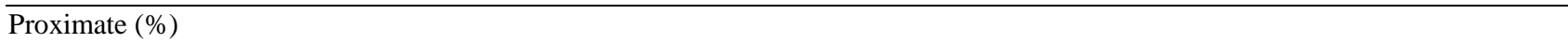 } \\
\hline Water & $72.10 \pm 1.16$ & $72.25 \pm 1.65$ & 0.334 & $71.88 \pm 1.64$ & $72.70 \pm 1.07$ & 0.162 & 0.466 \\
\hline Ash & $1.07 \pm 0.11$ & $1.04 \pm 0.30$ & 0.181 & $1.06 \pm 0.05$ & $1.04 \pm 0.09$ & 0.151 & 0.367 \\
\hline Fat & $5.64 \pm 0.88$ & $6.08 \pm 0.56$ & 0.000 & $5.95 \pm 0.82$ & $5.83 \pm 0.56$ & 0.000 & 0.000 \\
\hline Protein & $20.57 \pm 0.40$ & $20.39 \pm 0.55$ & 0.109 & $20.57 \pm 0.43$ & $20.30 \pm 0.57$ & 0.109 & 0.187 \\
\hline \multicolumn{8}{|l|}{ Physical } \\
\hline $\mathrm{pH}$ & $5.62 \pm 0.11$ & $5.56 \pm 0.04$ & 0.025 & $5.57 \pm 0.07$ & $5.60 \pm 0.09$ & 0.246 & 0.045 \\
\hline Drip loss (\%) & $5.35 \pm 0.53$ & $6.33 \pm 0.93$ & 0.060 & $6.10 \pm 1.19$ & $5.78 \pm 0.51$ & 0.599 & 0.123 \\
\hline Cooking loss $(\%)$ & $28.48 \pm 2.27$ & $30.01 \pm 2.06$ & 0.036 & $28.25 \pm 1.73$ & $30.66 \pm 2.08$ & 0.008 & 0.664 \\
\hline WBSF (kg) & $3.27 \pm 0.89$ & $3.12 \pm 0.66$ & 0.296 & $3.17 \pm 0.88$ & $3.18 \pm 0.90$ & 0.523 & 0.008 \\
\hline
\end{tabular}

KNP, Korean Native Black Pig; KNP×D, Korean Native Black Pig crossbred with Duroc; WBSF, Warner-Bratzler shear force.

${ }^{1}$ Values were presented as mean \pm standard deviation. ${ }^{2} \mathrm{p}<0.05$ was considered as significantly different.

gender on backfat thickness (Table 1). The difference in backfat thickness was mainly affected by gender. There were no significant difference in carcass conformation and quality grade between $\mathrm{KNP}$ and $\mathrm{KNP} \times \mathrm{D}$ as well as between barrows and gilts (Table 1). The differences slaughter and carcass weight and backfat thickness between breeds as well as gender did not result in higher carcass conformation and quality grades.

\section{Meat quality}

Fat content of $\mathrm{KNP} \times \mathrm{D}$ was higher $(\mathrm{p}<0.001)$ than that of KNP (Table 2). This showed that Duroc crossbred deposited more fat than KNP in the meat. This result might be due to the characteristics of Duroc as its meat contains relatively high intramuscular fat. This was in accordance with Alonso et al. (2009) who reported that Duroc crossbreed had higher intramuscular fat of Longissimus dorsi than that of other crossbreeds and Franco et al. (2014) who reported that Celta $\times$ Duroc crossbreed resulted in higher intramuscular fat than Celtaxlandrace crossbreed. Duroc is widely known as an alternative to traditional line pigs because of its specific characteristics, for instance, a high proportion of intra muscular fat (Barton-Gade, 1987; Blanchard et al., 1999). However, in our study, the high intramuscular fat content found in $\mathrm{KNP} \times \mathrm{D}$ did not improve the conformation and quality grade of $\mathrm{KNP} \times \mathrm{D}$.

Fat content of barrows was higher $(p<0.001)$ than that of gilts (Table 2). Barrows deposited more fat than gilts in the meat. Latorre et al. (2003a) and Barton-Gade (1987) also found that barrows had more intramuscular fat than gilts. In addition, Ellis et al. (1996) noted that barrows had higher marbling than gilts. There was interaction between crossbreeding and gender on the fat content (Table 2). There was a different level of fat deposition on the meat between breed and gender. KNP gilt showed higher fat content than KNP barrows whereas KNP $\times \mathrm{D}$ barrows showed higher fat content than $\mathrm{KNP} \times \mathrm{D}$ gilts (Figure 1).

The $\mathrm{pH}$ value of $\mathrm{KNP} \times \mathrm{D}$ was higher $(\mathrm{p}<0.05)$ than that

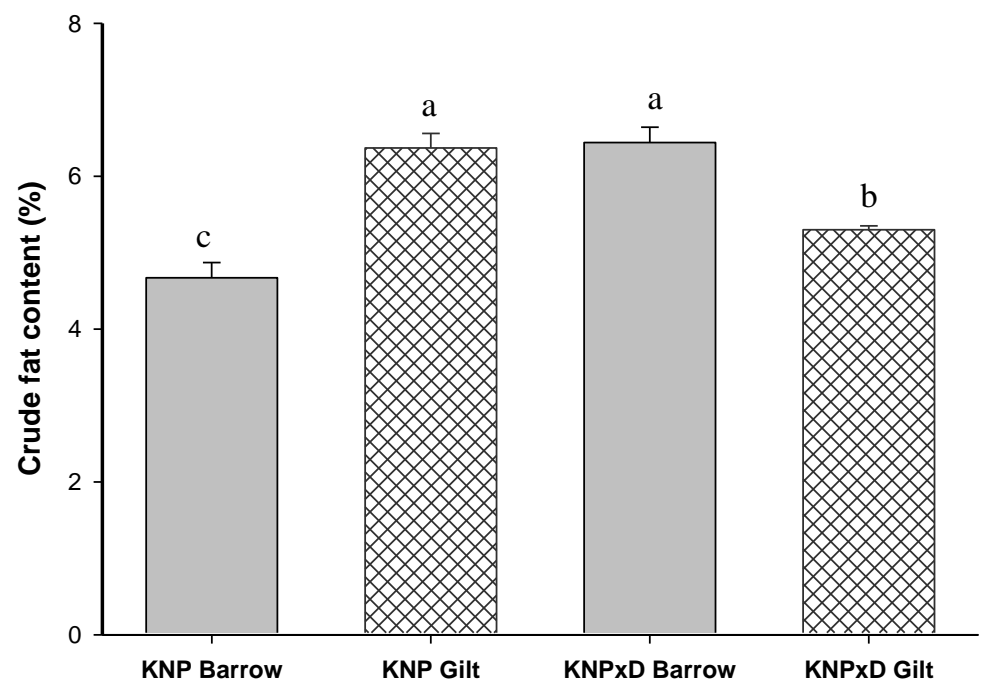

Figure 1. Crude fat content of Musculus longissimus dorsi of Korean Native Black Pigs (KNP) and its crossbred with Duroc (KNP $\times \mathrm{D})$. 
of KNP (Table 2). In contrast, Franco et al. (2014) found that there was no difference in $\mathrm{pH}$ value between Celta and Celta $\times$ Duroc. However, $\mathrm{pH}$ values of $\mathrm{KNP} \times \mathrm{D}$ and $\mathrm{KNP}$ were in the range of normal $\mathrm{pH}$ values of pork, i.e. 5.3 to 5.7 (Judge et al., 1989). There was no significant difference in $\mathrm{pH}$ value between barrows and gilts (Table 2). This was in accordance with Cisneros et al. (1996) and Alonso et al. (2009) who also found that there was no difference $\mathrm{pH}$ value between genders of pigs. Gender did not affect the $\mathrm{pH}$ value of meat.

There was no significant difference in drip loss between $\mathrm{KNP}$ and $\mathrm{KNP} \times \mathrm{D}$ as well between as barrows and gilts (Table 2). Bertol et al. (2013) found no difference in drip loss between Duroc-sired and others breed-sired pigs but Franco et al. (2014) found that drip loss of CeltaxDuroc was higher than that of Celta pig. Unruh et al. (1996) found that drip loss of barrows was greater than that of gilts but Franco et al. (2014) found that the drip loss was not influenced by gender. These conflicting reports indicate that breed and gender do not have much effect on drip loss.

The cooking loss of $\mathrm{KNP} \times \mathrm{D}$ was higher $(\mathrm{p}<0.05)$ than that of KNP and the cooking loss of barrow was lower $(\mathrm{p}<0.01)$ than that of gilt. However, there was no interaction between breed and gender on the cooking loss (Table 2). In contrast, Franco et al. (2014) did not found any difference cooking loss between CeltaxDuroc and Celta pig as well as between barrows and gilts.

There was no significant difference of WBSF between $\mathrm{KNP}$ and $\mathrm{KNP} \times \mathrm{D}$ as well as barrow and gilt (Table 2). There was no effect of crossbreeding on the WBSF. This might due to KNP meat itself as it is known for its tenderness and low shear force (Kim et al. 2011; Choi et al., 2011).

Lightness, redness, yellowness, chroma and hue angle values of meat of $\mathrm{KNP} \times \mathrm{D}$ were lower $(\mathrm{p}<0.001)$ than those of KNP (Table 3). This was in accordance with Franco et al. (2014) who reported that crossbreeding Celta with Duroc lowered the redness and yellowness of Celta pig. This might be due to the higher fat content of $\mathrm{KNP} \times \mathrm{D}$ compared to KNP meat (Table 2). Oliver et al. (1993) noted that a higher level of fatness has been associated with paler color of meat. Redness, yellowness and chroma values of meat of barrows were lower $(p<0.05)$ than those of gilts, but no effect of gender was found on the lightness and hue angle values (Table 3). In accordance with the effect of breed on fat and color, the lower color values of barrows might due to the higher fat content of barrow as compare to gilt (Table 2). There were interactions between crossbreeding and gender on redness, yellowness, chroma and hue angle values of meat but there was no interactions between breed and gender on lightness value of meat (Table 3 ). This might due to the interaction between crossbreeding and gender on the fat content of meat (Table 2).

Fresh meat color preference of KNP was higher $(p<0.001)$ than that of $\mathrm{KNP} \times \mathrm{D}$ (Table 3$)$. This might be due to the higher CIE values, especially the redness of KNP compared to that of $\mathrm{KNP} \times \mathrm{D}$ (Table 2). Mancini and Hunt (2005) stated that meat color is one of the most important quality parameters that determine the preference of meat by consumers and red color is associated with the freshness of meat. There was no significant difference in fresh meat color preference between barrows and gilts (Table 3 ). The lower redness, yellowness and chroma values of meat of barrow compared to gilt could not be detected by panelists. There was no interaction between crossbreeding and gender on the meat color preference (Table 3). The difference in meat color preference was mainly affected by crossbreeding.

There was no significant difference taste and texture preference between KNP and $\mathrm{KNP} \times \mathrm{D}$ as well as between barrow and gilt. Furthermore, there was no interaction

Table 3. Commission Internationale de I'Eclairage (CIE) color values and sensory properties ${ }^{1}$ of Musculus longissimus dorsi of Korean Native Black Pig and its crossbred with Duroc pig

\begin{tabular}{|c|c|c|c|c|c|c|c|}
\hline \multirow{2}{*}{ Items } & \multicolumn{2}{|c|}{ Crossbreeding effect (C) } & \multirow{2}{*}{$\mathrm{p}$ value $^{2}$} & \multicolumn{2}{|c|}{ Gender effect $(\mathrm{G})$} & \multirow{2}{*}{$\mathrm{p}$ value ${ }^{2}$} & \multirow{2}{*}{$\begin{array}{l}\mathrm{p}^{\mathrm{p}} \text { value }^{2} \text { of } \\
\text { interaction } \\
\quad(\mathrm{C} \times \mathrm{G})\end{array}$} \\
\hline & $\mathrm{KNP}^{2}$ & $\mathrm{KNP} \times \mathrm{D}^{2}$ & & Barrow & Gilt & & \\
\hline \multicolumn{8}{|l|}{ CIE color value } \\
\hline Lightness (L*) & $53.62 \pm 1.76$ & $52.01 \pm 2.33$ & 0.000 & $52.48 \pm 2.43$ & $52.31 \pm 2.09$ & 0.485 & 0.427 \\
\hline Redness $\left(a^{*}\right)$ & $10.55 \pm 1.81$ & $7.03 \pm 1.82$ & 0.000 & $7.62 \pm 2.16$ & $8.39 \pm 2.63$ & 0.029 & 0.002 \\
\hline Yellowness $\left(b^{*}\right)$ & $6.76 \pm 1.79$ & $4.12 \pm 1.31$ & 0.000 & $4.59 \pm 1.30$ & $5.10 \pm 2.47$ & 0.000 & 0.000 \\
\hline Chroma $\left(\mathrm{C}^{*}\right)$ & $12.56 \pm 2.41$ & $8.17 \pm 2.16$ & 0.000 & $8.91 \pm 2.45$ & $9.86 \pm 3.49$ & 0.000 & 0.000 \\
\hline Hue angle $\left(\mathrm{H}^{\circ}\right)$ & $32.30 \pm 3.72$ & $29.98 \pm 4.86$ & 0.000 & $31.06 \pm 3.94$ & $29.75 \pm 5.67$ & 0.567 & 0.000 \\
\hline \multicolumn{8}{|l|}{ Sensory properties ${ }^{3}$} \\
\hline Color & $6.9 \pm 0.7$ & $5.9 \pm 0.8$ & 0.000 & $6.3 \pm 0.9$ & $6.6 \pm 0.9$ & 0.218 & 0.678 \\
\hline Taste & $6.1 \pm 0.8$ & $6.2 \pm 0.8$ & 0.693 & $6.1 \pm 0.8$ & $6.2 \pm 0.8$ & 0.693 & 0.693 \\
\hline Texture & $6.1 \pm 0.8$ & $5.8 \pm 0.7$ & 0.141 & $6.0 \pm 0.7$ & $5.9 \pm 0.8$ & 0.831 & 0.831 \\
\hline
\end{tabular}

KNP, Korean Native Black Pig; KNP×D, Korean Native Black Pig crossbred with Duroc.

${ }^{1}$ Values were presented as mean \pm standard deviation. ${ }^{2} \mathrm{p}<0.05$ was considered as significantly different.

${ }^{3}$ 9-points hedonic scales: 1 (very bad) to 9 (very good). 
between breed and gender on meat taste and texture preference (Table 3). Latorre et al. (2003b) stated that Duroc was widely known as alternative to traditional lines pigs because of its appropriate sensorial characteristics. The present result showed that crossbreeding with Duroc did not affect the taste and texture of KNP meat.

\section{CONCLUSION}

Crossbreeding KNP with Duroc increased slaughter and carcass weights as well as dressing percentage without any effect on the backfat thickness and carcass grade. Barrows produced higher slaughter and carcass weights and backfat thickness without any difference in dressing percentage and carcass grade as compare to gilts. Barrow and gilt performed with similar responses to crossbreeding of KNP with Duroc on carcass traits. Crossbreeding KNP with Duroc increased fat deposition but decreased color values and preference of meat. Barrows were fatter but had lower color values and preference of their meat as compared to gilts. Crossbreeding of KNP with Duroc produces a better fat deposition in meat of barrows than in gilts.

\section{ACKNOWLEDGMENTS}

This research was supported by Gangwon Sanuri Center for Native Pig Cluster, Republic of Korea.

\section{REFERENCES}

Alonso, V., M. M. Campo, S. Espanol, P. Roncales, and J. A. Bealtran. 2009. Effect of cross breeding and gender on meat quality and fatty acid composition in pork. Meat Sci. 81:209217.

AOAC. 2007. Official Methods of Analysis. 18th ed, Association of Official Analytical Chemists, Washington, DC.

Barton-Gade, P. A. 1987. Meat and fat quality in boars, castrates and gilts. Livest. Prod. Sci. 16:187-196.

Bertol, T. M., R. M. L. de Campos, J. V. Ludke, N. N. Terra, E. A. P. de Figueiredo, A. Coldebella, J. I. dos Santos Filho, V. L. Kawski, and N. M. Lehr. 2013. Effects of genotype and dietary oil supplementation on performance, carcass traits, pork quality and fatty acid composition of backfat and intramuscular fat. Meat Sci. 93:507-516.

Blanchard, P. J., C. C. Warkup, M. Ellis, M. B. Willis, and P. Avery. 1999. The influence of the proportion of Duroc genes on growth, carcass and pork eating quality characteristics. Anim. Sci. 68:495-501.

Cameron, N. D., P. D. Warriss, S. J. Porter, and M. B. Enser. 1990. Comparison of Duroc and British Landrace pigs for meat and eating quality. Meat Sci. 27:227-247.

Choi, B. H., Y. M. Lee, M. Alam, J. H. Lee, T. H. Kim, K. S. Kim, and J. J. Kim. 2011. Detection of mendelian and parent-oforigin quantitative trait loci for meat quality in a cross between Korean Native Pig and Landrace. Asian Australs. J. Anim. Sci.
24:1644-1650

Cisneros, F., M. Ellis, F. K. McKeith, J. McCaw, and R. L. Fernando. 1996. Influence of slaughter weight on growth and carcass characteristics, commercial cutting and curing yields, and meat quality of barrows and gilts from two genotypes. J. Anim. Sci. 74:925-933.

DeHuidobro, F. R., E. Miguel, B. Blazquez, and E. Onega. 2005. A comparison between two methods (Warner-Bratzler and texture profile analysis) for testing either raw meat or cooked meat. Meat Sci. 69:527-536.

Ellis, M., A. J. Webb, P. J. Avery, and I. Brown. 1996. The influence of terminal sire genotype, sex, slaughter weight, feeding regime and slaughter-house on growth performance and carcass and meat quality in pigs and on the organoleptic properties of fresh pork. Anim. Sci. 62:521-530.

Franco D., J. A. Vaquezand, and J. M. Lorenzo. 2014. Growth performance, carcass and meat quality of Celta pig crossbred with Duroc and Landrance genotypes. Meat Sci. 96:195.202.

Hwang, I. H., B. Y. Park, S. H. Cho, J. H. Kim, Y. S. Choi, and J. M. Lee. 2004. Identification of muscle proteins related to objective meat quality in Korean native black pig. Asian Australs. J. Anim. Sci. 17:1599-1607.

Jin, S. K., C. W. Kim, Y. M. Song, W. H. Jang, Y. B. Kim, J. S. Yeo, J. W. Kim, and K. H. Kang. 2001. Physicochemical characteristics of longissimus muscle between Korean Native pig and landlace. Korean J. Food Sci. Anim. Res. 21:142-148.

Judge, M. D., E. D. Aberle, J. C. Forrest, H. B. Hedrick, and R. A. Merkel. 1989. Principles of Meat Science. 2nd ed., Kendall/Hunt Publishing Company. Dubuque, IA, USA.

Kim, S. W., X. P. Li, Y. M. Lee, Y. I. Choi, B. W. Choi, B. H. Choi, T. H. Kim, J. J. Kim, and K. S. Kim. 2011. QTL scan for meat quality traits using High-density SNP Chip analysis in cross between Korean Native Pig and Yorkshire. Asian Australs. J. Anim. Sci. 24:1184-1191.

Kim, G. D., B. W. Kim, J. Y. Jeong, S. J. Hur, I. C. Cho, H. T. Lim, and S. T. Joo. 2013. Relationship of Carcass Weight to Muscle Fiber Characteristics and Pork Quality of Crossbred (Korean Native Black Pig $\times$ Landrace) F2 Pigs. Food Bioprocess Technol. 6:522-529.

Korea Institute for Animal Products Quality Evaluation. 2010. http://www.ekape.or.kr/view/eng/system/pork.asp Accessed October 21, 2013.

Latorre, M. A., R. Lázaro, M. I. Gracia, M. Nieto, and G. G. Mateos. 2003a. Effect of sex and terminal sire genotype on performance, carcass characteristics, and meat quality of pigs slaughtered at $117 \mathrm{~kg}$ body weight. Meat Sci. 65:1369-1377.

Latorre, M. A., P. Medel, A. Fuentetaja, R. Lázaro, and G. G. Mateos. 2003b. Effect of gender, terminal sire line and age at slaughter on performance, carcass characteristics and meat quality of heavy pigs. Anim. Sci. 77:33-45.

Lee, S. K., Panjono, S. M. Kang, T. S. Kim, and Y. S. Park. 2008. The effects of dietary Sulfur and vitamin E supplementation on the quality of beef from the longissimus muscle of Hanwoo bulls. Asian Australs. J. Anim. Sci. 21:1059-1066.

Lo Fiego, D. P., P. Santoro, P. Macchioni, and E. de Leonibus. 2005. Influence of genetic type, live weight at slaughter and carcass fatness on fatty acid composition of subcutaneous adipose tissue of raw ham in the heavy pig. Meat Sci. 69:107114. 
Mancini, R. A. and M. C. Hunt. 2005. Current research inmeat color. Meat Sci. 71:100-121.

McGloughlin, P., P. Allen, P. V. Tarrant, and R. L. Joseph. 1988. Growth and carcass quality of crossbred pigs sired byDuroc, Landraceand Large White boars. Livest. Prod. Sci. 18:275-288.

Oliver, M. A., M. Gispert, and A. Diestre. 1993. The effects of breed and halothanesensitivity on pig meat quality. Meat Sci. 35:105-118.

Park, B. Y., N. K. Kim, C. S. Lee, and I. H. Hwang. 2007. Effect of fiber type on postmortem proteolysis in longissimus muscle of Landrace and Korean native black pigs. Meat Sci. 77:482491.

Peinado, J., P. Medel, A. Fuentetaja, and G. G. Mateos. 2008. Influence of sex and castration of females on growth performance and carcass and meat quality of heavy pigs destined for the dry-cured industry. J. Anim. Sci. 86:1410-1417.
Raj, St., G. Skiba, D. Weremko, H. Fandrejewski, W. Migdal, F. Borowiec, and E. Polawska. 2010. The relationship between the chemical composition of the carcass and the fatty acid composition of intramuscular fat of several pig breeds slaughtered at different weights. Meat Sci. 86:324-330.

RDA. 2001. Korean Native Black Pig (Standard farm textboo-121). Rural Development Admistration, Suwon, Korea, pp. 1-22.

SPSS. 2010. Statistical Package for Social Sciences for Windows (version 19.0). SPSS Inc., Chicago, IL, USA.

Suzuki, K., T. Shibata, H. Kadowaki, H. Abe, and T. Toyoshima. 2003. Meat quality comparison of Berkshire, Duroc and crossbred pigs sired by Berkshire and Duroc. Meat Sci. 64:3542.

Unruh, J. A., K. G. Friesen, S. R. Stuewe, B. L. Dunn, J. L. Nelssen, R. D. Goodband, and M. D. Tokack. 1996. The influence of genotype, sex, and dietary lysine on pork subprimal cut yields and carcass quality of pigs fed to either 104 or 127 kilograms. J. Anim. Sci. 74:1274-1283. 